\title{
Success: A 9 Layered-based Model of Giftedness
}

\author{
https://doi.org/10.3991/ijes.v5i4.7725 \\ A. Drigas $\left({ }^{\varpi}\right)$, M. Karyotaki \\ N.C.S.R. 'Demokritos', Agia Paraskevi, Athens, Greece \\ dreiit.demokritos.gr \\ C. Skianis \\ University of the Aegean, Karlovassi, Greece
}

\begin{abstract}
The current hierarchical structure of human cognition proposed is indicative of the multi - factorial and multi - layered construct of giftedness and intelligence. All individuals are intellectually endowed, but giftedness is perceived as an achievement in academic and practical intelligence as well as in the manipulation of wisdom-related skills and attitudes, taking into account nonintellective personal characteristics and contextual, sociocultural variables. Therefore, any attempt to measure intelligence should include multiple and diverse assessments comprising various psychological processes taking place in a specific time and place. Metacognitive processes are at the top of the hierarchy of cognition as their significance for one's quality of life and social progress is immense and their existence signals for a successful person. Moreover, metacognition requires handling for a confluence of knowledge, feelings and skills in a balanced way; this is the point where individuals need to pay special attention in order to be both personally and socially successful as well as psychologically healthy.
\end{abstract}

Keywords - intelligence, giftedness, cognition, metacognition

\section{Introduction}

The transition from one's natural abilities to giftedness and success is multifactorial and is interrelated to individual's personality and environmental contributions (Laine, 2010). Basically, someone is successful when he is able to balance his cognition, emotion as well as his personal goals and values to master his talents in a specific time and place (Csikszentmihalyi, 2000, Sternberg et al. 2002, Sternberg, 2000). The aim of the current proposal is individuals' cognitive development by taking into account their cognitive and emotional aspects. The hierarchy of abilities and skills depict the level of difficulty to achieve one's own level of giftedness that is to make the most of him and even more, to set the standards for the benefit of humanity. All individuals have a personal cognitive profile, which can reach a mastery level as long as certain intrinsic and extrinsic factors are favorable. Therefore, individuals need personalized learning experiences that can motivate them to self-regulate their inclinations and natural abilities. Moreover, self-regulation has been found to be a crucial 
factor for predicting personal excellence, thus its significance in the pyramid of abilities and skills is evident. Finally, the reason for emphasizing on metacognitive skills (Intrapersonal skills - Self-regulation skills - Universal Knowledge creation skills Self-transcendence - Unity consciousness) as top level skills is not only their significance and complexity, but their exceptional role in structuring a democratic society (Renzulli, 2002, Sternberg, 2004, Moran, 2009, Tannenbaum, 2000, Koltko-Rivera, 2006).

\section{Multi-faceted intelligence}

\subsection{Gardner's multiple intelligences}

Aydemir et al. made a research on students' multiple intelligences based on Armstrong's (2009) self-assessment scale. The aim of the study was to identify individuals' skills in various domains following Gardner's theory of multiple intelligences in relation to students' personal social status. Students' self-assessment process led them to conclude that naturalistic intelligence was the most prevalent type of intelligence among other types of intelligences. Furthermore, the current study made possible for their teacher to differentiate his teaching techniques as well as learning materials in order to improve students' overall performance. In advance, such scanning models can be a point of reference for the development of respective student's capacities.

Rile et al. proposed that the Theory of Multiple Intelligences should be integrated into the school or professional development curriculum for individuals with learning disabilities. According to recent findings, teaching styles and strategies that are driven by the aforementioned theory ended up with significant gains in students' with special needs reading skills, behavioral skills as well as self-reflection. Evidently, the Theory of Multiple Intelligences can offer more individualized learning curriculums that serve students' specialized needs. For example individuals with ADHD could be taught how to identify and manipulate their merits and weaknesses and become more successful in terms of their school performance and aspirations. However, students with learning disabilities in United Arab Emirates were rather unable to rate themselves in various types of intelligence, such as Naturalist, Musical, BodilyKinesthetic, Mathematical, Intrapersonal, Visual, Linguistics and finally, Interpersonal. Students' with special educational needs shall grow in knowledge, skills and motivation with adequate curriculum, training and assessment methodologies.

Bhebhe et al. stressed on the importance of differentiated and vocational oriented secondary school curriculum in Zimbabwe. The vocational curriculum consists in students' acquiring competences and practical, life skills concerning their vocation, family living as well as their social life, in general. The vocational path is illustrated on Gardner's Theory of Multiple Intelligences that assists in students' recognizing and developing various abilities and talents.

Zhang initiated a multiple fuzzy evaluation index system of physical education in higher education based on the multiple intelligences theory. The aim of the study was to verify that this evaluation index system was efficacious and feasible in addition to 
assessing and improving students' talents through physical education in key colleges and universities. According to the evaluation standard of physical education, there are qualitative and quantitative indicators corresponding to four layers of ranking; excellent, good, mediocre and poor.

Starks presented a unified model for designing effective serious games, taking into account Bandura's social cognitive elements as well as the theory of Multiple Intelligences by Gardner. More specifically, the goals of the serious games are centered on users' gaining knowledge, outcome expectations, social support and self-efficacy through adequate sound and graphics, body-sensors as well as narrative, humor and personal reflection elements. Self-efficacy is the belief about one's ability to accomplish goals and is interrelated to sense of mastery and observational learning. The aforementioned factors are facilitators of self-efficacy and self-efficacy is an underlying or a primary outcome of play.

Petruta applied the Multiple Intelligences Theory to school children as far as their learning methodology is concerned so as to raise their school performance. The adaptations in teachers' methodology regarded their instruction material and techniques as well as their didactic tools. The results of the study showed that the teaching methodology, the didactic tools and the subjects taught were related to the enhancement of a different type of intelligence. In addition, the verbal, logical and visual intelligence were the most prevalent in students' improved performance.

Sheahan et al. made an exploratory research on nursing students' clinical skills after implementing a multiple intelligences teaching approach (MITA). The research team integrated Gardner's MI theory into nursing education through creating special rubrics with mental representations or schemata, opt for enhancing the particular skill being taught; critical inquiry, problem solving and self-reflection skills. As a result, the experimental group was more active and intrigued with the personalized learning material than the control group so that the former achieved higher examination results in their final assessment.

\subsection{Gardner's multiple intelligences \& Sternberg's triarchic intelligence}

Virtop looked into students' dynamics in linguistic and logical-mathematical intelligences by administrating a MIDAS questionnaire before and after implementing a syllabus based on the B.S. Bloom taxonomy of educational objectives. More specifically, the instructive material and methodology towards the Romanian language and literature as well as towards the English language was in accordance with students' evaluation process. Moreover, students' linguistic sensitivity, writing and reading skills were combined with creativity and practical skills, thus teachers considered that students' educational needs should be addressed to as a whole, mainly, through group work. Likewise, in reference to problem solving and calculus skills from the perspective of students' logical-mathematical intelligence, comprehension and spatial intelligence were necessary for any of the lessons and types of evaluation. Therefore, beyond any doubt, all skills are interrelated and are interwoven in a holistic way so that the absence or lack in some of them may hinder the progress of the others and the 
opposite. As a result, a teaching style such as group work may lead to students' overall improvement as it is comprises trans-disciplinary skills and strategies.

Jessurun et al. adapted and expanded the Munich Model of Giftedness (MMG) by Heller and Hany (1986), bringing about a more universal model for human talent expression. This Universal Model of Giftedness encompasses one's potentialities in reference to his cultural environment, his age as well as his level of creativity. According to Gardner, giftedness denotes one's expertise in a domain and one can be creative and innovative if he has achieved mastery in a domain. Thus, creativity, expressed in different forms, corresponds to high intelligence and even more, to giftedness. Renzulli $(1978,2002)$ included perseverance and commitment to a task in the notion of giftedness. Therefore, personality characteristics, motivation, self-concept and control-expectations in combination with environmental conditions have a detrimental effect on personal achievement, the product of high intelligence. Thus, the above modifiable and adaptable mechanisms constructing oneself, are incorporated into intelligence and share a common denominator; metacognition and its relation to intelligence. Intelligence is an applicable variable, thus its measurement should be based on the various forms of its expression and the mediating factors affecting it. However, measuring talents and reaching a conclusion on the notion of intelligence and its layers are debatable as talents are latent. Measuring talents would worth studying in an attempt to combat chronic underachievement, rather than measuring intelligence per se.

Macnamara made an overview of the theories regarding intelligences and mindfulness thinking in order to enhance human interaction and relationships (public relations). Gardner proposed that educators have to address learners' need to be respectful and ethical so as to balance disciplinary knowledge, creativity and synthesis of large amounts of information. Therefore, Gardner places great emphasis on bridging emotion and cognition with the aim to assist individuals' living, managing and interacting with other people. Human intelligence is thus, a multi-facet notion that can be applied in everyday life, but along with reality, is subjected to human perspective. Mindfulness, which consists in affective and cognitive elements and processes, is influenced by one's standpoint that is one's position in a society. Overall, the human mind as the element that enables someone to be aware of the world and his own experiences, to think and to feel, incorporates emotional, interpersonal, intrapersonal, spatial, naturalistic, social, cultural and humanistic dimensions of human thought and behavior.

\subsection{A global deliberative space of intelligence}

Lemaignan et al. presented a coherent and consistent system for human-robot interaction through the Beliefs, Desires, Intentions (BDI) architectures. The main principle of building a human-aware deliberative layer was to embrace models of human behavior and human preferences in order to develop an effective artificial cognition for a robot. All cognition-related modules live in the same global deliberative space, although the architecture encompasses lower-level modules to execute actions or manage sensors. This robot is able to serve and interact seamlessly with humans through bidirectional, decisional components bound together by the knowledge they 
produce and consume. At run-time, the knowledge available to the robot originates from three sources: a priori knowledge stored in an ontology; a second part of the knowledge is acquired from perception, interaction and planning and the third source are inferences produced by the reasoner. Therefore, human-robot communication, collaboration and human-aware execution lay on human-level semantics as well as on a set of cognitive skills; internal cognitive skills (reasoning, theory of mind, memory management), skills pertaining to acquiring and anchoring knowledge in the physical world, multi-modal communication and situated dialogue, human-aware task planning and, finally, robot execution control. Either in an interactive grounding task or in a richer decision-making task, context-dependent memory or, in other words, autonoetic consciousness remains a first class priority for artificial intelligence as the robot is able to reflect upon its own past or future experiences.

Lombardi et al. introduced an empirical model to predict the system behavior on unseen examples in the design of real-world decision support systems. This dataextracted, empirical model from the Machine Learning Domain was then embedded into an optimization model, thus bridging the gap between predictive and prescriptive analytics. In general, modeling Machine Learning requires obtaining a training set, choosing the features to be used as input, choosing a Machine Learning Technique and finally, proceeding with the training and the evaluation. As a result, an Empirical Model Learning (EML) based system upgrades the search process as well as the quality of the final solutions in a complex real-world setting. Active learning incorporated in the EML approach, could provide the system with an autonomous and selfadapting capacity as well as the predictive capacities of the Machine Learning models could be further exploited to improve robustness and reliability of the real world, decision making systems.

Bowe et al. proposed a holistic, systemic view in medical students' assessment and evaluation as well as in guiding program decision making. This sustainable assessment framework is structured on health carers' competencies in compliance with curriculum improvements, effective program performance and program decision making. Moreover, active engagement of diverse stakeholder groups, students, faculty and curriculum directors, shall lead to their developing problem solving, critical and selfreflection skills. Even more, a central construct of systems theory is systems thinking, which is the ability to recognize the influence of component complexity, dynamic interrelationships and situational context on system outcomes. Therefore, the healthcare system can operate efficiently as long as decision making lays on internal correction within individual component performance, quality improvement in system performance and system readiness to respond to changes in the system's external environment.

\section{$3 \quad$ Layered types of intelligence}

Kos et al. investigated on the effects of the Layered Curriculum on students' achievements both in the short and in the long run. The theory of multiple intelligences by Gardner constitutes the foundation of the Layered Curriculum, developed by 
Nunley in 2003. According to the aforementioned curriculum, learners encounter tasks with progressive degree of difficulty in various areas. At the first level, learners must acquire basic knowledge and vocabulary. At the second level, learners must implement and arrange their knowledge, taking advantage thus, of their problem solving and other top level skills. Finally, learners must be able to be creative and critical, which correspond to the most complicated level of thinking. Each of the three levels is evaluated through rubrics and open-ended questions revealing students' knowledge and extent of competence on a subject. Moreover, active and cooperative learning lays on the existence of multiple learning techniques, methods and styles, depending on students' preferences and interests. As a result, a highly motivating and tailormade learning processes accompanied by the promotion of self-assessment and selfrecognition skills created a democratic environment that enhanced students' achievement.

Thorisson introduced a computational model of real-time, task-oriented, psychosocial dialog skills called Ymir. This model supports the creation of autonomous computer characters with full-duplex, real-time, face-to-face interaction with a human. Ymir incorporates multimodal perception, decision and multimodal action in a coherent framework. Therefore, a character created in this architecture should be able to fluently combine its communication and task skills as well as it should be able to cancel or modify any of its own actions at a moment's notice. The modules in Ymir are distributed into four process collections; a Reactive layer (RL), a Process Control layer (PLC), a Content layer (CL) and an Action Scheduler (AS). Reactive layer processes refer to sensory data processes occurring on timescales and their accompanying, reactive decisions. The Process Control layer encompasses more complex computations tied to controlling the process of the dialog. Knowledge bases in the Content layer interpret input about a specific domain and produce actions in response to the content of the input. The Action Scheduler produces specific motor morphologies following the behavior lexicon. Bottom-up analysis of data is achieved through Blackboards, whereas top-down control is achieved through the Covert Deciders. This control does not go through the Blackboards. It assists in guiding lower level, semiautomatic processes from a higher level and serves as a way to direct the attention of the character. As a result, the main advantage of the current model lays on its flexibility to execute long chains of actions incrementally, including its real-time performance, task knowledge and action selection at multiple levels of granularity so that many types of communicative, task-knowledgeable agents can be supported.

Delgoshaei et al. implemented a multiple-intelligence approach in preschool education with the aim to develop children's cognitive skills. The main purpose of the multiple-intelligence based educational methods was students' analyzing and solving their problems as well as getting ready for future, real tasks. Preschool children must explore the world around them on their own in order to discover and interpret relations and events in their surroundings. Sensual experiences pass through observation and perception skills so that logical argumentation and basic knowledge is constructed. Furthermore, by developing higher cognitive skills, such as sequential thinking, problem solving, concept application and creativity in preschool children, their performance on the test of cognitive development by Venita Kaul, was improved in all as- 
sessed fields; their senses, their memory and observation skills, their basic concept formation as well as sequential thinking and problem solving skills.

Jung et al. drew attention to creativity as a higher cognitive skill, which correlates with intuition and reflection for enhancing the manufacture of competitive products and inducing the capacity of organizations. Design Convergence Talents (DCTs) are individuals, who are talented in creative-convergence design and possess a degree in design. Moreover, creative convergence is the ability to incorporate different fields and explore new values via tolerance and a willingness to form new knowledge in order to solve problems. Thus, design majors with field expertise can assume a leading role for innovation in the entire business operation as they can merge business activities and engineering in an interdisciplinary way. In this sense, creativity is tied to cognitive, environmental and intrinsic affective characteristics that can be nurtured through strengthening speaking and writing skills as well as spatial skills. Therefore, it seems that developing someone's basic competences can lead to his improvement in design creativity as well. Thus, being creative, also called design thinking, encompasses not only to think creatively in a specific field, but also to exploit the interrelationship between several types of intelligence, called creative convergence.

Bosse et al. initiated a modeling format that expresses direct temporal or causal dependencies among "emotion", "feeling" and "feeling a feeling" (core consciousness). According to Damasio's approach, emotion is an internal emotional state with multiple facets or dimensions as a reaction to a certain stimulus, whereas feeling is sensing one's body and cognitive state by constructing mental images, unconsciously. Core consciousness is the realization of someone's body state on account of the emotion caused by a stimulus. Thus, the individual becomes consciously aware of the feeling. These neural states or, in other words, these representations are described and presented dynamically, over time and space. The relational specification of the functional role of a mental state property concerns relationships both backward and forward in time. Therefore, the perceived temporal relationship between a thought and an action is claimed to be a main source for the experience of ownership of an action. Moreover, core consciousness is accompanied by other high-level cognitive functions, such as reasoning, planning and language processing. This approach can assist in possible verification of global dynamic properties (specifying the content representation of internal states) in real-world situations.

Pylvas et al. investigated on air traffic controllers' vocational expertise and excellence based on Gagne's Differentiated Model of Giftedness and Talent (DMGT) and Gardner's Multiple Intelligence (MI) theory. The current study illustrated that the process of developing natural abilities (gifts) into vocational and professional skills (talents) is closely related to one's self-regulation skills. As natural abilities, linguistic, cognitive, spatial, intrapersonal, musical, bodily-kinesthetic and interpersonal abilities were taken into consideration accompanied by intrinsic and extrinsic goalorientation, volition as well as control and efficacy beliefs. In regard to intellectual abilities, logical-mathematical and intrapersonal abilities (understanding of one's own skills, capacities and feelings, self-reflecting) were considered most important characteristics for vocational expertise and excellence. In addition, interpersonal skills, which is a socioaffective characteristic was also emphasized for its significance to air 
traffic controllers' vocational expertise and excellence. However, motivation and volition proved to be stronger among the employees representing vocational excellence. More specifically, competent self-regulators apply their vocation-specific skills and their cognitive skills in practice and regulate their own performance. Therefore, self-regulatory abilities, motivation and volition are intertwined and in combination with vocation-specific skills can lead to employees' vocational excellence in their chosen career.

\section{$4 \quad$ Research highlights}

Intelligence is a multi-faceted construct encompassing one's natural abilities, affected by non-cognitive characteristics and environmental conditions (Pylvas, 2015, Jessurun, 2016)). Thus, intelligence cannot be measured as one single entity or conceived as an unchangeable, theoretic notion. Intelligence is a holistic, applicable notion in everyday life and its facets are interrelated (Macnamara, 2016, Delgoshaei et al. 2012 ). However, hierarchy in one's abilities and skills refers to his success in achieving an overall quality of life. Therefore, an intelligent person is far beyond being only clever. He must acquire many attributes that function synergistically with his cognitive profile to create a personal identity, incorporated in his own environment. A gifted person, thus, is someone with the affordances and the potential described above, integrated into his environment. In other words, humans are complicated human beings that should be acknowledged of their individuality and uniqueness.

Furthermore, giftedness can be regarded as a state of mind, in which individuals have full understanding of their strengths and weaknesses as far as cognition and emotion is concerned. The most important aspect of giftedness and predictor of its impact on society is its actual use. As a result, giftedness could be conceived as the set of choices that someone made throughout a lifetime with the aim to reach excellence both for himself and humanity. In other words, a just and fair society lays especially on the spatial, interpersonal, naturalistic intelligence as well as respectful, ethical and creative minds proposed by Gardner and core consciousness included in Damasio's theory of emotion, feeling and core consciousness.

In advance, giftedness is most certainly tied to self-regulatory abilities, embracing one's motivation towards self-regulation and self-reflection (Pylvas, 2015). When self-generated thoughts, feelings and actions are planned and systematically adapted to affect one's learning and motivation, self-regulation is achieved. Motivation assists learners to formulate decisions and promote decision-making accompanied by volitional processes, which guide the subsequent enactment of the decision. Moreover, self-reflection is congruent with intrapersonal skills, which correspond to one's need to form attribution interpretations for success or failure (Pylvas, 2015, Macnamara, 2016). Critical reflection on one's own experiences carries two important benefits for the individual; first, these self-reactions are under one's own control and strengthen one's tolerance of stress and commitment to the task, thus help the learner to identify the best coping strategies in a given situation and enhance his self-efficacy (Starks, 
2014). Second, individual and communicative learning may occur through perspective transformation of experiences, feelings and thoughts (Macnamara, 2016).

\section{Conclusions}

In view of Gardner's MI theory, Sternberg's theory of Successful Intelligence, Gagne's Differentiated Model of Giftedness and Talent (DMGT) as well as Heller's Munich Model of Giftedness (MMG), the current research team proposed the following Layered-based Model of giftedness :

This model emphasizes on a hierarchy of the multi-facet construct of intelligence, based on the significance of its type of intelligence on one's personal wellbeing and success in life (Maslow, 1962).

The concept of success is perceived as a sociological construct and is understood more as an outcome than a dynamic, developmental process. Global Success theory suggests that the identification and multi-dimensional analysis of one's personal values (axiological system) throughout his life, is important for understanding the interrelationship between success and giftedness. Global Success is multi-determined insofar as the complex human personality is biologically, psychologically, culturally and socially multi-determined. The individualized character of Global Success reflects the uniqueness of each individual and is tied to an individualized curriculum for gifted learners (Cretu, 2009).

The basic notion is that intelligence is translated into applicable skills, further separated into two basic categories: cognitive components (abilities, higher cognitive skills, and giftedness) and meta-cognitive components (an integrated construct of selfconsciousness and emotional intelligence).

The reason for the hierarchy presented is illustrated on the aforementioned theories that drew attention on one's handling of competencies according to the environmental surroundings. Furthermore, cognitive flexibility accompanied by an adaptable character and fruitful external condition may lead to one's personal growth. Therefore, giftedness in this sense surpasses intellectual excellence and interweaves natural abilities manipulation with regulating one's set of personal virtues, knowledge and feelings. As a result, sensing one's own state of mind and others', in balance, is at the top of the hierarchy of human skills; because of its difficult realization as well as its significance for the person and whole society.

The layers correspond to a set of abilities and skills, ranked on account of their difficulty to acquire and their significance on multi-level cognitive experiences. Cognitive experience is a psychological basis of intellectual giftedness and a type of representation (i.e., how an individual sees, understands, and interprets what is going on in the surrounding reality) is a proto-phenomenon of the intellectual life of a person (Shavinina et al., 1996).

On the first level, natural abilities set the grounds for every individual's basic knowledge formation. On the second level, individuals transform the acquired knowledge according to their level of cognitive development. They are able to deal with everyday tasks in an efficient way. On the third level, lay critical and creative 
thinking skills, which lead to academic success (Kaufman et al. 2008). The following layers compose individual's metacognitive skills; metacognitive skills are at the top of this hierarchy because it has been found that they can distinguish expertise from excellence (Pylvas, 2015).

More specifically, individuals need to realize that they have made a serious progress in a field and need to be aware of the feelings accompanying their status (intrapersonal intelligence). Self-regulation signifies someone's need to exceed expertise and lead himself and other people towards excellence. Furthermore, this is the point where individuals need to reflect on their strengths and weaknesses and reframe or reconstruct reality (Sternberg's Facets of Creativity). Self-control and self-monitoring is essential for the above process (Manning, 1996). Talents arise when someone develops his cognitive skills at a mastery level so that he can be creative in his own field of expertise.

Knowledge engineers have the responsibility to articulate the society's conceptual umbrella: the grand concepts expressed in highly universal and abstract terms identify the common features linking seemingly disparate activities into a coherent whole (Quinn, 1992). Quinn called this conceptual umbrella a "future vision" that gives to the society's intellectual members some challenges for intellectual growth and develops their capacity for continuous change. Leaders' ability to maintain continuous selfreflection in a wider perspective is indispensable when it comes to increasing the quality of knowledge created in a society. Leaders provide the direction for justifying the value of knowledge that is being developed constantly by the society based on a higher-order value system (discrimination of truthfulness or goodness) and thus, they set the standards for acquiring, creating, exploiting and accumulating new knowledge continuously and repeatedly in a circular process (universal knowledge).

What's more, the person who has a positive view of self, who is open to experience, who is creative, who is trustworthy and responsible, who has values, who is well informed and who is aware that he is in the process of becoming is the person most able to survive and deal with an uncertain future, (Maslow, 1962).

Decreasing reliance on externals for self-definition, increasing interiority, and spirituality corresponds to self-transcendence (Beaumont, 2009, Frank1, 1966). Selftranscendence has proved to impact self-actualization in terms of the full development of the individual self (Alexander et al. 1991). A leader senses the effects of his decisions and actions as well as balances his cognitive and affective aspects (attentional control) in order to assist others to self-actualize. On the first hand wisdom-based skills and practical skills as top-level, metacognitive skills, on the other hand altruism and social progress may offer an alternative prospect for protecting the democracy in the benefit of future generations (Kaufman et al. 2008, Renzulli, 2002, Koltko-Rivera, 2006). Wisdom has a dynamic nature and is interwoven with the stream of life. A change in personality, ideology or hierarchy of values directly affects its structure, introduces a new quality into it as well as necessitates its re-specification and redefinition. Existence modifies wisdom and wisdom regulates one's existence (Sekowski et al., 2011). A wise person acquires cognitive, social and emotional qualities, the application of which in everyday life will bring full satisfaction and well-being in his life (Sekowski et al., 2011). 
At the level of unity, contradictions disappear (that is the definition of unity, all opposites get united) and only one quality remains, the pure positivity, pure happiness (http://tm-ireland.org/the-highest-human-experience/). Furthermore, the dialectical unity of knowledge encompassing the dynamic construction of personal knowledge through movement and communication in a space (insights, principles, values, beliefs, practices) reflects the strength of its community of learners; the community of learning entails knowledge simultaneously distributed and personalized, dispersed but not attenuated, directed but also reciprocal (Balchin et al., 2009, Sekowski et al., 2011).

Therefore, giftedness cannot be conceptualized as an intellectual product rather than a dynamic process based on learning and development in a complex, reciprocal interaction of the person and the environment (Yun Dai, 2012).

Globalization entails one's need to acquire and balance several cognitive skills, such as creative thinking skills, analytical skills, practical skills as well as wisdombased skills (Ambrose et al. 2016).

By layering natural abilities and skills in a school curriculum, students' school performance is improved in the short and in the long run (Kos, 2014).

All cognitive abilities and skills are dynamic in nature and interrelated. Also, all individuals acquire all types of intelligences in various levels (Macnamara, 2016).

Self-efficacy is an essential mediator or an underlying outcome of one's excellence or success (Jung et al. 2017).

The way to the final stages of human cognition (from the bottom to the top) can be accelerated through educational interventions, even from preschool years. Thus, students can build on their skills and knowledge in a variety of interesting ways with the aim to capitalize on their strengths and compensate for their weaknesses (Kaufman et al. 2008).

The current model describes the principles of an optimal learning environment, wherein tailor-made, active and constructive learning environment exists (Bhebhe et al. 2014, Aydemir, 2014, Petruta, 2013, Virtop, 2015, Sheahan, 2015, Delgoshaei et al. 2016, Rile L. G. et al. 2015).

According to "The Seven Stages of Psychological Development" by Richard Barrett, there is a large amount of research showing that our ability to master the first three stages of development, significantly affects our ability to master the later stages. In other words, your infant/child/teenager experiences significantly affect your ability to find happiness in adult life.

The first and most obvious long-term effect of using more of our full mental potential are the measurable results in terms of our mental capacities, such as practical intelligence, field independence, mental efficiency, fluid intelligence and creativity (Intelligence, vol. 29, pp.419-440, 2001).

Giftedness entails academic intelligence (analytical, creative skills and attitudes), practical intelligence (the capacity to execute ideas and convince others of their value) and wisdom-related skills and attitudes (the capacity to produce ideas that look for common good instead of only personal good). Therefore, giftedness measurement should entail analytical, creative, wisdom and task-commitment skills in as specific or various domains (Kaufman et al. 2008). 
Gifted individuals are characterized by their superiority in a specific field and their ability to converge other disciplines and produce innovative ideas (Jung et al. 2017).

Values-based decision-making allows individuals to create a future that resonates deeply with who they really are. It creates the conditions that allow one's authenticity and integrity to flourish (Barrett, 2015).

As a conclusion, there is a clear need for expanding the concept of giftedness and of counteracting the real difficulties involved in such expansion as far as the school setting is concerned (Getzels et al., 1958).

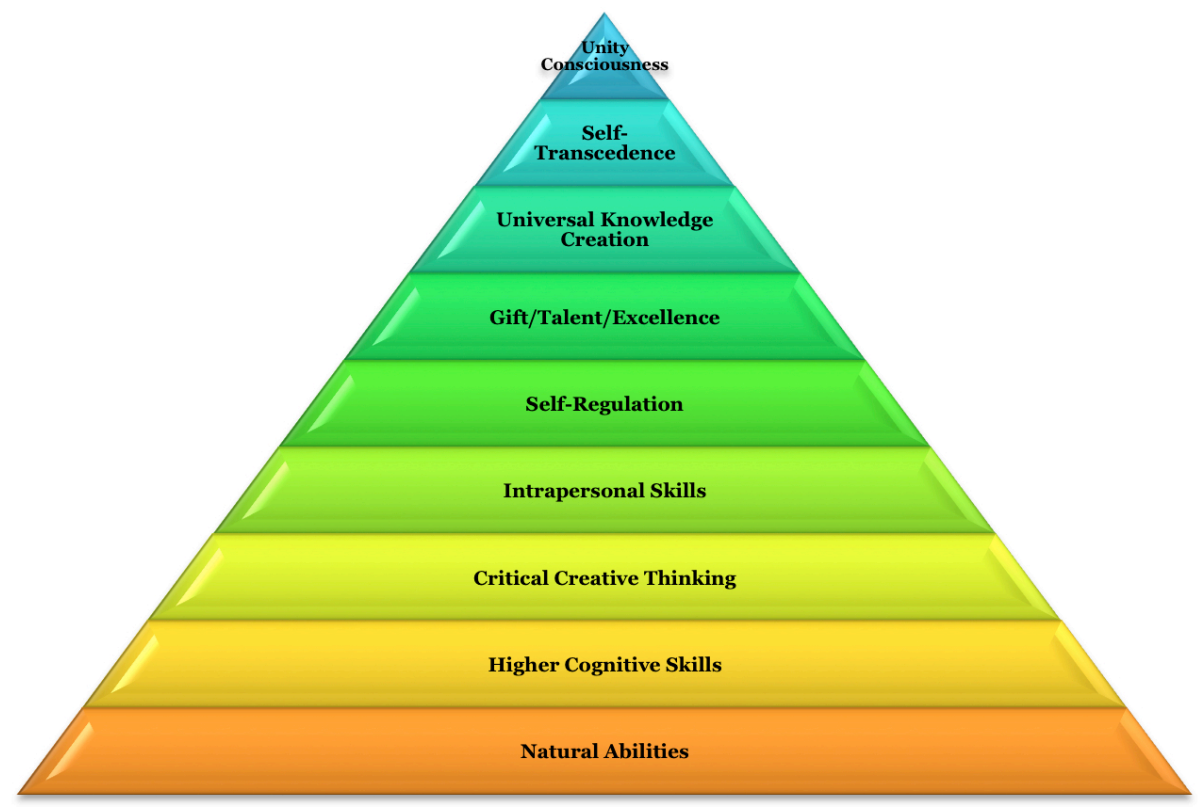

Fig. 1. The 9-layer pyramid: Natural abilities (intellectual-socioaffective-sensorimotor), Higher Cognitive Skills (Sequential thinking/Problem solving/Embodiment), Critical/Creative Thinking, Intrapersonal skills (understanding of one's own skills, capacities and feelings), Self-regulation (motivation, volition, self-reflection), Gift/Talent/Excellence in a field/Sternberg's Facets of Creativity (Sternberg, 2003), Universal knowledge creation (discovering future visions, truthfulness or goodness in knowledge), Self-transcendence (the use of our full mental and spiritual potential, wisdom-based skills by Sternberg (Ambrose et al. 2016)), Unity consciousness (feeling a feeling, complete inner peace): connectedness to all humanity and nature).

\section{References}

[1] Alexander C. N. Rainforth M. V. and Gelderloos P. : "Transcendental meditation, selfactualization and psychological health: A conceptual overview and statistical metaanalysis", Journal of Social Behavior and Personality; Corte Madera, CA6.5 (Mar 1, 1991): 189 . 
[2] Ambrose D. \& Sternberg R. J.: Creative Intelligence in the 21st Century-Grappling with Enormous Problems and Huge Opportunities", Sense Publishers 2016, The Netherlands. https://doi.org/10.1007/978-94-6300-506-7

[3] Aydemir H. and Karali Y. : "Study of secondary school students' multiple intelligence areas (Malatya case), Procedia-Social and Behavioral Sciences, vol. 152, pp. 167-172, 2014. https://doi.org/10.1016/j.sbspro.2014.09.175

[4] Balchin T. Hymer B. and Matthews D. J. : "The Routledge International Companion to Gifted Education", Routledge, 2009.

[5] Barret R. : "The Values-driven Organization: Unleashing Human Potential for Performance and Profit" London: Fulfilling Books, 2014.

[6] Barrett R. "The Metrics of Human Consciousness”, Lulu Publishing, 2015.

[7] Beaumont S. L. : "Identity Processing and Personal Wisdom: An Information-Oriented Identity Style Predicts Self-Actualization and Self-Transcendence", An International Journal of Theory and Research, vol. 9, issue 2, pp. 95-115, 2009. https://doi.org/10.1080/ 15283480802669101

[8] Bhebhe S. Dziva M. and Maphosa C. : "Towards a Differentiated and Vocational Oriented Secondary School Curriculum in Zimbabwe”, Mediterranean Journal of Social Sciences, vol. 5, n. 7, 2014.

[9] Bosse T. Jonker C. M. and Treur J. : "Formalisation of Damasio's theory of emotion, feeling and core consciousness", Consciousness and Cognition, vol. 17, pp. 94-113, 2008. https://doi.org/10.1016/j.concog.2007.06.006

[10] Bowe C. M. and Armstrong E. : "Assessment for Systems Learning: A Holistic Assessment Framework to Support Decision Making Across the Medical Education Continuum", Academic Medicine, vol. 92, n. 5, pp. 585-592, 2017. https://doi.org/10.1097/ACM.00000 00000001321

[11] Cretu C. : "Global success and giftedness". In The Routledge International Companion to Gifted Education”, Balchin T. Hymer B. and Matthews D. J.”, Routledge, 2009.

[12] Csikszentmihalyi M. Rathunde K. and Whalen S. : "Talented Teenagers: The roots of success and failure", Cambridge University Press, 2000.

[13] Delgoshaei Y. and Delavari N. : "Applying multiple-intelligence approach to education and analyzing its impact on cognitive development of pre-school children", ProcediaSocial and Behavioral Sciences, vol. 32, pp. 361-366, 2012. https://doi.org/10.1016/ j.sbspro.2012.01.054

[14] Drigas A. Karyotaki M. \& Skianis Ch.: "Attentional control and other executive functions", iJET, vol. 12, n. 3, 2017.

[15] Frankl V. E. : "Self-transcendence as a human phenomenon", Journal of Humanistic Psychology, vol. 6, issue 2, 1966. https://doi.org/10.1177/002216786600600201

[16] Getzels J. W. and Jackson P. W. : "The Meaning of 'Giftedness: An Examination of an Expanding Concept”, The Phi Delta Kappan, vol. 40, number 2, pp. 75-77, 1958.

[17] Jessurun J. H. Shearer C. B. and Weggeman M.C.D.P. : “A Universal Model of Giftedness-an adaptation of the Munich Model”, High Ability Studies, vol. 27, n. 2, pp. 113-128, 2016. https://doi.org/10.1080/13598139.2015.1108184

[18] Jung J. H. and Chang D. R. : "Types of creativity-Fostering multiple intelligences in design convergence talents", Thinking Skills and Creativity, vol. 23, pp. 101-111, 2017. https://doi.org/10.1016/j.tsc.2016.12.001

[19] Kaufman S. B. and Sternberg R. J. : "Conceptions of Giftedness". In the Handbook of Giftedness in children, pp. 71-91, SpringerLink, 2008. https://doi.org/10.1007/978-0-38774401-8 5 
[20] Koltko-Rivera, M. E. : "Rediscovering the later version of Maslow's hierarchy of needs: Self-transcendence and opportunities for theory, research, and unification", Review of General Psychology, vol. 10, issue 4, pp. 302-317, 2006. https://doi.org/10.1037/10892680.10.4.302

[21] Kos E. S. and Sahin A. E. : "The Effect of Layered Curriculum Supported by Multiple Intelligences on Students' Achievements and Permanence", Education and Science, vol. 39, n. 174, pp. 286-296, 2014.

[22] Laine S. : "The Finnish public discussion of giftedness and gifted children", High Ability Studies, vol. 21, issue 1, 2010. https://doi.org/10.1080/13598139.2010.488092

[23] Lemaignan S. Warnier M. Sisbot E. A. Clodic A. and Alami R. : "Artificial cognition for social human-robot interaction: An implementation", Artificial Intelligence, vol. 247, pp. 45-69, 2017. https://doi.org/10.1016/j.artint.2016.07.002

[24] Lombardi M. Milano M. and Bartolini A. : "Empirical decision model learning", Artificial Intelligence, vol. 244, pp. 343-367, 2017. https://doi.org/10.1016/j.artint.2016.01.005

[25] Macnamara J. : "Multiple intelligences and minds as attributes to reconfigure PR-A critical analysis", Public Relations Review, vol. 42, pp. 249-257, 2016. https://doi.org/10.1016/ j.pubrev.2015.03.002

[26] Manning BH. Glasner SE. Smith ER.: "The self-regulated learning aspect of metacognition: A component of gifted education”, Roeper Review, 1996. https://doi.org/10.1080/ 02783199609553741

[27] Maslow A. H. : "Some basic propositions of a growth and self-actualization psychology" in Perceiving Behaving Becoming: A New Focus for Education, 1962.

[28] Moran S. : "Purpose: giftedness in intrapersonal intelligence", High Ability Studies, vol. 20, issue 2, 2009. https://doi.org/10.1080/13598130903358501

[29] Nonaka I. : A dynamic Theory of Organizational Knowledge Creation”, Organization Science, vol. 5, No. 1, pp. 14-37, 1994. https://doi.org/10.1287/orsc.5.1.14

[30] Petruta G. P. : "Multiple intelligences stimulated within the lessons by the practicing students from the Faculty of Sciences", Procedia-Social and Behavioral Sciences, vol. 76, pp. 676-680, 2013. https://doi.org/10.1016/j.sbspro.2013.04.185

[31] Pylvas L. Nokelainen P. and Roisko H. : "The role of natural abilities, intrinsic characteristics and extrinsic conditions in air traffic controllers' vocational development", Journal of Workplace Learning, vol. 27, n. 3, pp. 241-263, 2015. https://doi.org/10.1108/JWL-072013-0049

[32] Quinn, J. B. : Intelligent Enterprise, New York: Free Press, 1992.

[33] Renzulli J. S. : "Emerging conceptions of giftedness: Building a bridge to the new century”, Exceptionality, vol. 10, issue 2, 2002. https://doi.org/10.1207/S15327035EX1002 2

[34] Renzulli J. S. : "Expanding the Conception of Giftedness to Include Co-Cognitive Traits and to Promote Social Capital", PDK, vol. 84, issue 1, 2002.

[35] Rile L. G. Catalan-Opulencia M. J. Decenorio N. M. and Tan N. L. : "Multiple Intelligences of Students with Learning Disabilities: Its Implication for Business Curriculum Development in United Arab Emirates", Procedia-Social and Behavioral Sciences, vol. 23, pp. 894-898, 2015.

[36] Sekowsi A. and Knopik T. : "The psychology of giftedness and the psychology of wisdom: one or multiple perspectives?". In Ziegler A. and Perleth C. "Excellence: essays in honor of Kurt A. Heller", Deutsche Nationalbibliothek, 2011.

[37] Shavinina L. V. and Kholodnaja M. A. : "The Cognitive Experience as a Psychological Basis of Intellectual Giftedness", Journal for the Education of the Gifted, vol. 20, issue 1, pp. 3-35, 1996. https://doi.org/10.1177/016235329602000102 
[38] Sheahan L. While A. and Bloomfield J. : "An exploratory trial exploring the use of a multiple intelligences teaching approach (MITA) for teaching clinical skills to first year undergraduate nursing students", Nurse Education Today, vol. 35, pp. 1148-1154, 2015. https://doi.org/10.1016/j.nedt.2015.05.002

[39] Starks K. : "Cognitive behavioral game design: a unified model for designing serious games", Frontiers in Psychology, vol. 5, article 28, pp. 1-10, 2014.

[40] Sternberg R. J. : "Successful Intelligence: A unified view of giftedness". In Developing talent across the life span, Cornelis F. M. van Lieshout, Peter G. Heymans, Psychology press, 2000.

[41] Sternberg, R. J. : "Wisdom, intelligence, and creativity synthesized", New York: Cambridge University Press, 2003. https://doi.org/10.1017/CBO9780511509612

[42] Sternberg, R. J. : "Wisdom and giftedness". In Beyond knowledge: Extracognitive aspects of developing high ability, Shavinina L. V. and Ferrari M. Lawrence Erlbaum Associates, 2004.

[43] Sternberg, R. J. Grigorenko E. L. : "The Theory of Successful Intelligence as a Basis for Gifted Education", Gifted Child Quarterly, vol. 46, issue 4, 2002. https://doi.org/10.1177/ 001698620204600403

[44] Tannenbaum A.J.: "A history of giftedness in school and society". In International Handbook of Giftedness and Talent, Heller K. A. Monks F. J. Sternberg R. J. and Subotnik R. F., Elsevier, 2000. https://doi.org/10.1016/B978-008043796-5/50003-6

[45] Thorisson K. R. : "Mind model for multimodal communicative creatures and humanoids", Applied Artificial Intelligence, vol. 13, pp. 449-486, 1999. https://doi.org/10.1080/ 088395199117342

[46] Virtop S. A. : "Possibilities of Instruction Based on The Students' Potential and Multiple Intelligences Theory", Procedia-Social and Behavioral Sciences, vol. 191, pp. 1772-1776, 2015. https://doi.org/10.1016/j.sbspro.2015.04.223

[47] Yun Dai D. : "Giftedness in the making: a response to Ziegler and Phillipson”, High Ability Studies, vol. 23, issue 1, pp. 47-50, 2012.

[48] Zhang Y. : "A Multiple Fuzzy Evaluation Model of Physical Education in General Colleges and Universities for Knowledge Engineering", Chemical Engineering Transactions, vol. 46, pp. 589-594, 2015.

\section{$7 \quad$ Authors}

A. Drigas is a Research Director at N.C.S.R. 'Demokritos', Institute of Informatics and Telecommunications, Telecoms Lab - Net Media Lab, Agia Paraskevi, 153 10, Athens, Greece (e-mail: dr@iit.demokritos.gr).

M. Karyotaki is a Phd candidate in cognitive skills with N.C.S.R. 'Demokritos', Institute of Informatics and Telecommunications, Telecoms Lab - Net Media Lab, Agia Paraskevi, 153 10, Athens, Greece (e-mail: karyotakimaria@gmail.com).

C. Skianis is an Associate Professor in the Department of Information and Communication Systems Engineering at the University of the Aegean, Karlovassi, Greece (e-mail:cskianis@aegean.gr).

Article submitted 20 September 2017. Published as resubmitted by the authors 14 November 2017. 